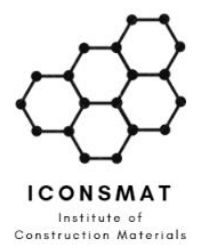

\title{
Recycled Aggregates from Construction and Demolition Waste in the Production of Concrete Blocks
}

\author{
Juan A. Ferriz-Papi ${ }^{1 *}$, Simon Thomas ${ }^{1}$ \\ ${ }^{1}$ School of Architecture, Built Environment and Natural Environment; University of Wales Trinity Saint \\ David, Swansea, UK
}

*Corresponding author: Juan A. Ferriz-Papi; E: juan.ferriz-papi@uwtsd.ac.uk

\begin{abstract}
The construction industry generates large amounts of waste, usually mixed, which can be composed of different origin materials, most of them catalogued as non-hazardous. The European Union targets for this waste for 2020 have been already achieved by the UK, but it is mainly developed in downcycling processes (backfilling) whereas upcycling (such as recycle in new concrete batches) still keeps at a low percentage. The aim of this paper is to explore further in the use of recycled aggregates from construction and demolition waste (CDW) in concrete mixes so as to improve upcycling. A review of most recent research and legislation applied in the UK is developed regarding the production of concrete blocks. As a case study, initial tests were developed with a CDW recycled aggregate sample from a CDW plant in Swansea. Composition by visual inspection and sieving tests of two samples were developed and compared to original aggregates. More than $70 \%$ was formed by soil waste from excavation, and the rest was a mix of waste from mortar, concrete, and ceramics with small traces of plaster, glass and organic matter. Two concrete mixes were made with $80 \%$ replacement of recycled aggregates and different water/cement ratio. Tests were carried out for slump, absorption, density and compression strength. The results were compared to a reference sample and showed a substantial reduction of quality in both mixes. Despite that, the discussion brings to identify different aspects to solve, such as heterogeneity or composition, and analyze them for the successful use of these recycled aggregates in the production of concrete blocks. The conclusions obtained can help increase upcycling processes ratio with mixed CDW as recycled aggregates in concrete mixes.
\end{abstract}

DOI: 10.36756/JCM.v2.1.6 (C2020 Institute of Construction Materials

\section{Keywords}

Recycled aggregate, concrete, concrete block, construction and demolition waste, recycling. 


\section{Introduction}

Construction and demolition waste (CDW) is a major concern as the heaviest and most voluminous waste stream in the European Union (EU). According to the European Commission, the amount of CDW generated is estimated in about $25-30 \%$ of the total waste in the EU. It includes different types of waste such as concrete, ceramics, gypsum, wood, glass, metals, plastics, solvents, asbestos or excavated soil, which can be often mixed. According to the statistics from the UK Department for Environment, Food and Rural Affairs (DEFRA), the UK produced 55 million tonnes of non-hazardous CDW in 2014 excluding excavation waste. The environmental impact produced is mainly related to land occupation and contamination, resource scarcity and biodiversity destruction, but for the construction industry, it is also a big issue to solve as it needs to be managed properly with increasing taxes and expenses [1].

The European Waste Framework Directive [2] states that all Member States should achieve at least 70\% of non-hazardous CDW recovery, excluding soil waste. The UK achieved 89.9\% in 2014 (DEFRA statistics) and already complies with this mandatory regulation. CDW Recovery is divided in two different method groups: backfilling and recycling. Backfilling can be considered as downcycling because the material application is of low value. On the other hand, with upcycling, this waste is transformed into new materials and products that increase its value. It is more beneficial to apply upcycling not only for the market itself but also to increase the number of products produced with this waste and therefore increasing the demand of it as source material [3]. In the UK, 75\% recovery was for backfilling in 2014, whereas $25 \%$ was recycled.

One solution for CDW high-value recycling is to use it as recycled aggregates for concrete. The main problem is that CDW characteristics are different to original aggregates, and composition and heterogeneity are big variables that affect enormously the possibilities to apply it as source material [4]. For this reason, it is needed to assess waste properties separately and then in the concrete mix to know suitability for this use.

The aim of this paper is to work further research on recycled aggregates application in concrete mixes for the production of concrete blocks with non-structural application. For this purpose, a literature review is developed following recent publications in this field. A case study is developed over a recycled aggregate sample which contains large quantities of excavated soil mixed with other types of waste from CDW. Idoneity of this aggregate is analyzed for this purpose and compared to the results obtained in other different investigations.

\section{Literature review}

CDW is often mixed, resulting in what is called as recycled aggregates (RA). Silva et al. [4] explains that the best applications for RA are in landscaping, road pavements and mortar/concrete. In the last use, material heterogeneity is further increased respect to natural aggregates and can cause larger problems in concrete, but affirms that some positive results have been obtained, considering crushed concrete aggregates as a good example. Generally, when incorporating masonry rubble (such as ceramics or light-weight concrete), mechanical strength is thought to be reduced. Asphalt, gypsum, metals, plastic, rubber, soil or wood are considered as contaminants and can degrade the concrete strength drastically. For this reason, selective demolition is strongly recommended so that this recycled aggregate can be implemented properly in concrete mixes. Automatic sorting of the CDW, addition of environmental chemical admixtures, and other technological advancements had been studied by Sartipi et al. as well [26-45]. In their studies a precise focus had been placed on economic added values as well. 


\section{A. Recycled Crush Concrete}

The use of recycled crush concrete as recycled aggregate in concrete mixes has been widely explored. This is the main waste type used in concrete mixes, also known as recycled crush concrete aggregates (RCA). The constituents of RCA are original aggregates and adhered mortar.

The RILEM committee [5], [6] established some recommendations when proportioning concrete mixes with RCA. A summary of them is as follows:

- A higher standard deviation should be used for a mean strength to achieve a required characteristic strength whenever variable-quality recycled aggregates are used.

- When only coarse recycled aggregates are used (natural sand is not replaced), then the free $\mathrm{w} / \mathrm{c}$ ratio will be the same as for conventional aggregates.

- To achieve the same slump, 5\% increase of water is needed with recycled aggregates.

- The sand-to-aggregate ratio will be the same as for natural aggregates.

- It will be mandatory to develop trial mixes and appropriate adjustments according to the source and properties of recycled aggregates.

CIRIA [3] points out initial considerations for concrete incorporating RCA. Workability, compressive strength and deformation are not considered to be affected with not more than $20 \%$ of coarse aggregate replacement. Higher replacement proportions will bring to reduction in quality. Regarding durability, it is not affected for concrete of equal compressive strength and $\mathrm{w} / \mathrm{c}$ ratio, irrespective of the percentage aggregate replaced.

BS 8500 [7] incorporates RCA specifications for concrete mixes and also explains that it should be assessed case-by-case considering its specific composition. Other countries also incorporate restrictions and recommendations for the use of RCA in concrete mixes, such as EHE 08-Appendix 15 [8] in Spain, which makes similar description of requirements for RCA to replace coarse aggregates and conditions for quality assurance in the concrete mix for structural purposes. In both standards, replacement is limited to a maximum of $20 \%$ of coarse aggregates only.

Recent research explains the performance of this RCA in concrete mixes accurately. Etxeberria [9] affirms that structural behavior and durability are two factors to consider in the use of RCA. Structural behaviour depends on the percentage of RCA used, and durability depends on the heterogeneity of the recycled particles. For that, physical, mechanical, and chemical properties of original coarse aggregates need to be identified as well as original fine aggregates present in adhered mortar.

Etxeberria et al. [10], [11] also state that density and absorption are affected by the quality of the adhered mortar, and porosity is affected by the $\mathrm{w} / \mathrm{c}$ ratio of the recycled concrete used. The crushing procedure and particle size also has an influence in the amount of adhered mortar. On the other hand, the use of RCA in dry conditions affects workability to a larger extent. The shape and texture can also affect workability. Reduction of $\mathrm{w} / \mathrm{c}$ ratio can help keep the same compression strength increasing the replacement proportion of coarse RCA, but not in the case of fine and coarse aggregate replacement, in which an increase of cement content is needed to keep the same resistance.

Rao et al. [5] describe some important characteristics of RCA, such as water absorption (ranged from 3 to $12 \%$ ), size distribution and abrasion resistance.

Shahidan et al. [12] state that water absorption of RCA is higher than natural aggregates, and density is lower. 
Kumar [13] specifies that the maximum nominal size of the RCA influences the amount of mortar attached to the recycled aggregate. For this reason, it is difficult to make broad conclusions for the use of these type of aggregates.

\section{B. Crushed Brick and Masonry Rubble}

Use of recycled aggregates from masonry rubble for new concrete mixes compromises quality of the final product. CIRIA [3] makes a compilation of standards and characteristics of this type of recycled aggregates, and the main recommendation is not to be incorporated in concrete. RILEM [6] establishes different types of recycled aggregates depending on the existing proportion of masonry rubble and establish some specifications about allowable contaminants for each type. For type 1 (mainly composed of masonry rubble), this waste can only replace up to $10 \%$ of original aggregates.

Khalaf and DeVenny [14] affirm that crushed brick aggregate is very porous and absorbs large quantities of water, therefore this can affect workability. Other authors [11], [15], [16] discuss about conditions of concrete mixing regarding the water content of this aggregate. It seems to affect flexural strength and freeze-thaw performance mainly. In this case, Barra de Oliveira and Vazquez [16] recommend to have semisaturated conditions for this aggregate.

In general, compressive strength is reduced at earlier stages with the use of this recycled aggregate, but increases along time, probably because of any pozzolanic effect [17]. Tensile strength is slightly increased [15] and so does for shear strength in structural elements [17].

Mueller et al. [18] propose the use fine-grained masonry rubble as light-weight aggregate for structural concrete. Results in this research showed comparable performance to conventional lightweight concrete.

\section{Other Types of CDW}

Most of other types of CDW are considered as contaminants inside recycled aggregates for concrete mixes. They commonly affect quality reducing properties and increasing the dispersion of results:

- Gypsum increases the quantity of sulphates in the concrete mix. Sulphate expansion can break concrete.

- Wood or any other organic material are unstable in concrete and introduce large amounts of air apart from other organic substances.

- Metals can get rusted, expand, and break concrete.

- Glass is difficult to separate as density is similar to stone and brick. It is more likely to have higher percentages in recycled sands. It is specified not to exceed $1 \%$ by mass [19]. However, it is feasible to use glass as aggregate replacement with good results obtaining what is called as "glasscrete" [20]. Despite that, plate glass can be potentially dangerous because it can take part in alkalisilica reactions [21].

- Plastics are nowadays studied to be used as aggregates in concrete. They reduce quality of the mix but can be used for non-structural purposes [19].

- Asphalt seriously reduces the strength of concrete. It is recommended that bitumen content should not exceed $1 \%$ by mass [19], [21].

- Soils can be harmful mainly when they contain clay. Clay content in aggregates can damage cement bound and reduce strength considerably.

CIRIA [3] mentions gypsum, wood, metals and plastic as main contaminants and must be eliminated or reduced to minimum in the aggregates. For this, they recommend to establish processes of separating and sieving in CDW plants. Metals can be separated by magnetic means. Organic materials (wood and 
plastic) can be separated by air blowers, water processing or by hand [19]. In the case of asphalt, it is recommended to eliminate it from the recycled aggregates. The bituminous concrete layers should be removed by coldmilling before recycling. This will help split and separate aggregates much more, although it does not eliminate asphalt from its surface. When recycling this aggregate in new asphalt, it does not need to be removed and can be recycled completely [21]. Finally, in the case of soils, they should be washed and clay reduced as much as possible [19].

Monalisa et al. [22] discuss about the reasons why these techniques are not so wide implemented and difficulties in the construction industry to use recycled aggregates. In this way, efforts from administration and other institutions are being put in place to increase recycling. The Quality Protocol of Aggregates from Inert Waste [23] is an example of good practice with recycled aggregates with different composition in different applications to achieve good quality. The Concrete Block Association (CBA) [24] compiles a set of recommendations for concrete aggregate block sustainability including the use of recycled aggregates.

\section{Experimental Programme}

In this experimental programme, there were three main stages to develop. The first stage was the collection and analysis of recycled aggregates to use. The second stage was the design of concrete mixes and elaboration of samples. Finally, there were a set of tests in physical and mechanical properties.

\section{A. Materials}

The recycled aggregates were obtained from a CDW plant in Swansea (UK). One sample of about 100 $\mathrm{kg}$ was taken to the laboratory inside impervious bags. In the lab, the samples were kept isolated until the time to use it. Visual inspection was used to calculate proportion of different waste types. Tests for absorption and particle size distribution (BS EN 933-1:2012 and BS EN 933-2:1996) were also developed and compared to Füller's curve.

The cement used was Portland CEM I. The natural aggregates were standard for construction. Particle size distribution tests were also developed to both fine and coarse aggregates. Mixing water used was ordinary tap water. No additives were introduced in the mix.

\section{B. Mixes Design}

Two mixes were designed with the purpose to investigate the performance of this recycled aggregate in concrete mixes. An equal proportion of natural aggregates was replaced by recycled aggregates in both mixes, reaching to $80 \%$ (of both fine and coarse aggregates). The difference between these two mixes was the $\mathrm{w} / \mathrm{c}$ ratio, keeping cement content constant and modifying water content to get $\mathrm{w} / \mathrm{c}$ ratios of 0.6 (sample A) and 1.0 (sample B). Recycled aggregates were added dry so as not to modify these ratios and study performance. Additionally, a reference sample was made with $100 \%$ of natural aggregates and $0.6 \mathrm{w} / \mathrm{c}$ ratio.

The mix quantities were calculated by the absolute volume method, obtaining a cement:sand:gravel ratio of 1:1.7:3.3. To calculate the quantity of natural aggregates to replace, both fine and coarse aggregates were summed and replaced by an equal part of recycled aggregates up to $80 \%$.

The concrete mix was mixed in a sequential manner, in which water was first put in the mixer, then cement and mixed for one minute, and finally aggregates and mixed again. 


\section{Tests}

Fresh concrete was tested to slump (BS EN 12350-2:2009). Cubic samples were made and cured in a water tank (BS EN 12390-1:2012, BS EN 12390-2:2009). With these samples, tests were developed to absorption, density (BS EN 12350-6:2009) and compression strength at 7 and 28 days (BS WN 123904:2000).

\section{Results and Discussion}

\section{A. About the Recycled Aggregates}

The main concern for the recycled aggregates was about composition. By visual inspection, it could be determined that more than $70 \%$ of these recycled aggregates were composed of soils. Other existing types of waste were mortar/concrete (15\%), ceramics (9\%) and some traces of contaminants such as gypsum, glass, wood and asphalt, although the quantities of these contaminants were small (a total of $3 \%)$. Soils were both fine and coarse aggregates. It was observed that some parts were adhered to the higher grains, what indicated the presence of clay. A reduction in concrete properties was already guessed at that point due to clay content, sulphates from gypsum, and organic matter [19], [21]. Despite that, the purpose of this study was the analysis of the whole recycled aggregate so no modification was developed.

Analyses of absorption were developed to different parts of the sample and obtained a range of results between $2.8 \%$ and $7.6 \%$. This wide range could happen because of the aggregates exposition to weather conditions on site and because of the aggregate heterogeneity. Porosity of recycled waste helps to keep water, but also clay can retain water easily. The varying content of each element could produce this difference between the sub-samples, and therefore changed the water absorption capacity.

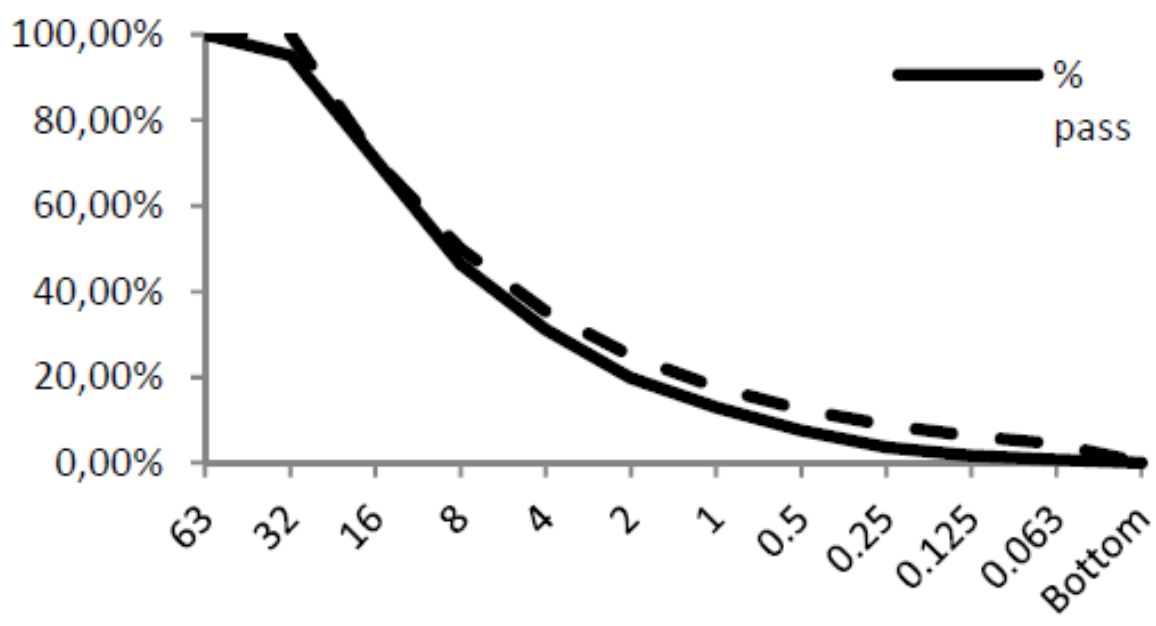

Figure 1 Particle size distribution of recycled aggregates compared to Füller's curve

Regarding the gradation of the aggregate, it was compared to Füller's curve (Fig. 1). They were near, some scarcity of fine aggregates was evident though. Despite that, the sieving process showed a large quantity of fines adhered to coarse aggregates and also to the sieves. As it was developed in dry conditions, large amounts of dust coming from sieving happened during the test process. Although the results did not show it, it was evident the high content of adhered fines that were released during the sieving process and projected to the air. 


\section{B. About the Concrete Sample Tests}

Compressive strength at 28 days was substantially decreased in both samples: $60 \%$ in sample $A$ and $71 \%$ in sample $B$. The increase of water content affected the results much as a decrease in compression strength was observed in sample B, about $28 \%$ respect to sample A (Fig. 2). On the other hand, slump was very different in each mix: $13 \mathrm{~cm}$ in the reference sample, $2.5 \mathrm{~cm}$ in sample $A$ and 23 in sample $B$.

There are several circumstances affecting this reduction of strength. As commented before, two main aspects were composition and heterogeneity of the recycled aggregate. Clay content could have reduced the binder adherence. Besides, the presence of contaminants increased sulphates and asphalt content, as well as other organic matter from wood and plants that can affect porosity and cement reaction.

Water content also introduced porosity in the mix, which contributed to strength reduction. The larger water content, the larger porosity, and therefore the bigger reduction in strength. However, sample A was difficult to compact and voids appeared on side surfaces as a consequence. This could have also contributed to reduce strength. Workability was much better in sample B and helped concrete to adapt better to the mould surfaces.

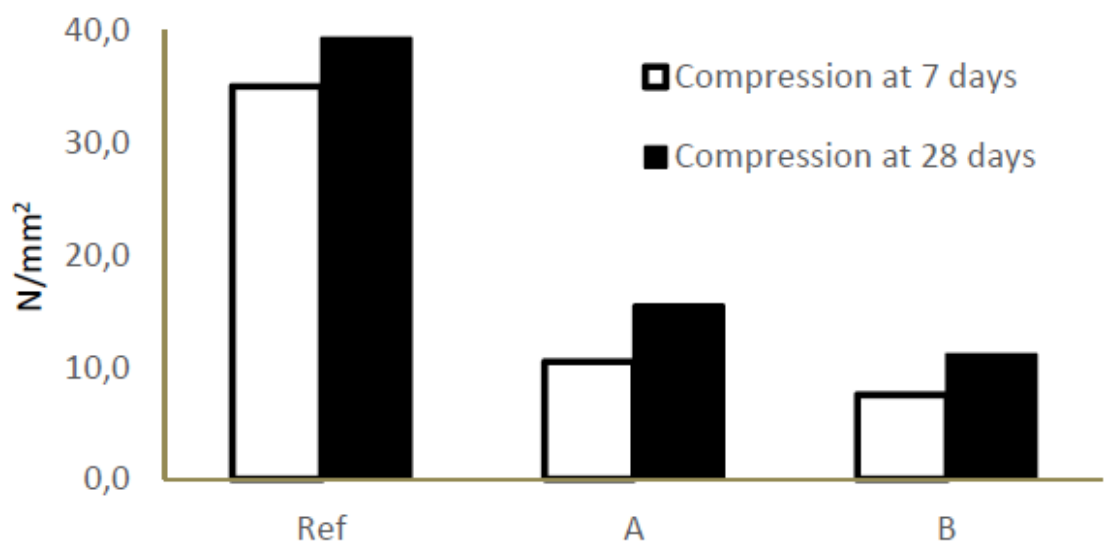

Figure 2 Compressive strength at 7 and 28 days

Another factor to consider was that recycled aggregates were dried and then added to the mix. Etxeberria et al. [10], [11] suggested that these dried aggregates would absorb water very avidly and reduce cement hydration affecting final strength. Hydration could be recovered in the curing process with water along time.

It could be observed in samples A and B that there was a growing compression strength between 7 and 28 days which was proportionally greater than in the reference sample. The cement hydration that did not happen due to the previous fact with water absorption could have been activated in the curing tank and therefore increased this hydration process. Besides, as suggested by Zakaira et al. [17], any pozzolanic reaction could have happened and improved mechanical strength. This is more evident in sample $A$, where this compression strength difference between 7 and 28 days is $21 \%$ bigger. 


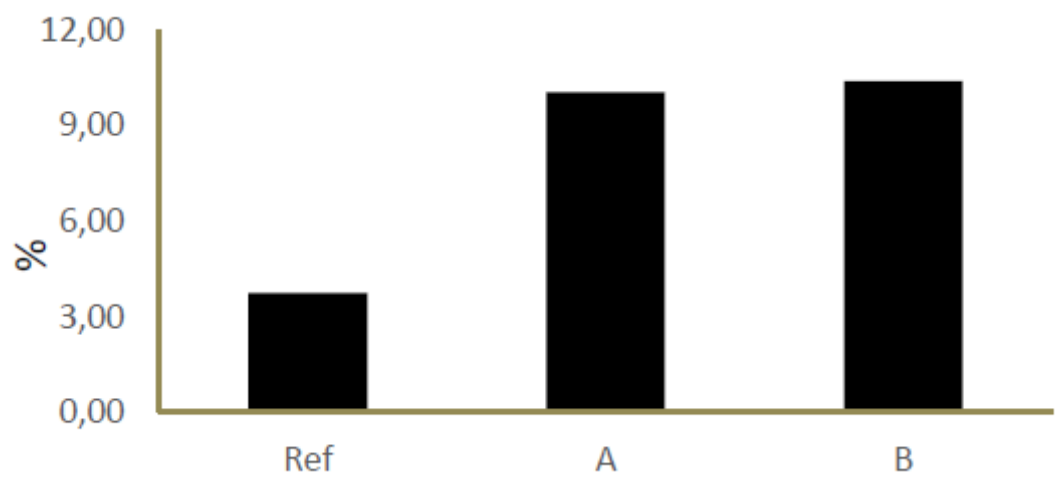

Figure 3 Water absorption of concrete samples

Deviation of results raised with recycled aggregates in samples A and B. As before, this could have been as a consequence of composition and heterogeneity that could cause different proportions of different types of waste in every sample.

Absorption was also drastically increased up to about 3 times respect to the reference sample. It was evident a big growth of porosity due to the type of aggregates and the increase in water content. Density was, therefore, also affected. There was a big difference between density and bulk density, showing an increase of porosity in the sample surfaces.

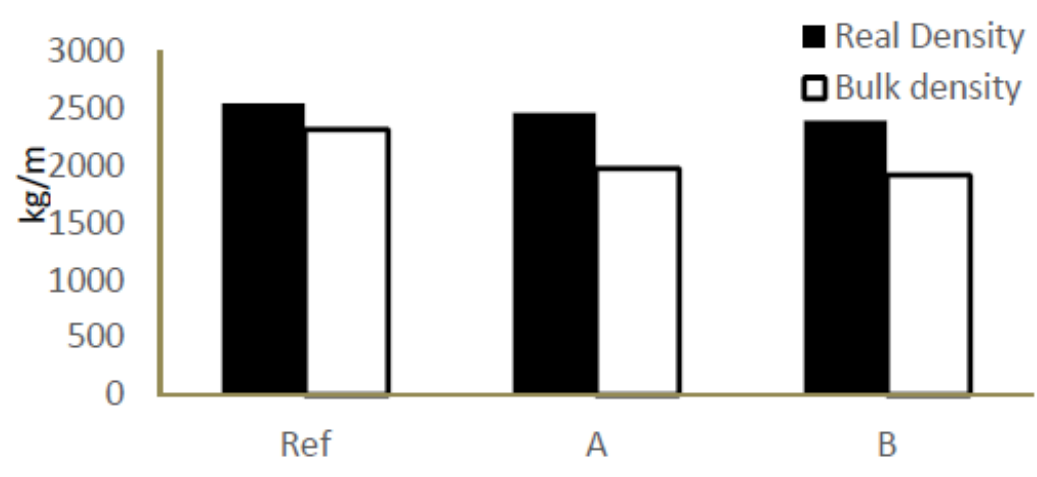

Figure 4 Density of concrete samples

\section{Recommendation}

According to the results shown, the following recommendations can be made for the use of these recycled aggregates in concrete mixes:

- The reduction of compression strength is evident. There is the need to test samples with less recycled aggregates replacement. Quantities up to $50 \%$ replacement could be tested, although recommendations from other authors and standards go for not more than $20 \%$.

- Dispersion should be studied to know the range of results that can happen in these recycled aggregate properties. It is needed to take as many samples as needed to get a better correlation of the results with this recycled aggregate [25]. Important properties to analyze are, among others, composition, absorption, porosity, density, fines content, clay content, chlorides content, sulphates content and abrasion.

- Recycled aggregate quality can be increased. Looking at actual composition, first process of contaminant separation should be developed, that is to eliminate the quantity of gypsum, glass, wood and asphalt, or at least reduce it to not more than $1 \%$. Crushing and sieving would help 
get appropriate gradation for concrete compacity. Finally, a wash process would help eliminate the quantity of clay and fines in the recycled aggregates or reduce it to minimum.

- Replacement of only coarse aggregates is advisable, although it is not the only possibility. Other investigations are being developed working about the replacement of sand by fine recycled aggregates in the case of mortar and self compacting concrete. This would be another field of study that has not been developed in this paper.

- Fresh concrete workability should be controlled. Increase of water content brings to an increase of porosity and a reduction of quality. The $\mathrm{w} / \mathrm{c}$ ratio should be kept low. Superplasticizers can be used with this purpose. Additionally, an increase of cement content will also grow quality whenever the $\mathrm{w} / \mathrm{c}$ ratio is kept constant.

- The introduction of dried recycled aggregates in the concrete mix can result in dried mixes with little workability, and therefore cement hydration is damaged. It is important to control humidity in recycled aggregates and avoid mixing them dried. The best option is to introduce them in the concrete mix in semi-saturated conditions [16]. For this, storage should be covered and isolated from the ground, and absorption controls should be developed as well as procedures to keep this humidity as constant as possible. Additionally, the test of particle size distribution should be developed in different conditions, probably wet, to avoid dust and loss of fine particles in the process.

- These recycled aggregates are not recommended for structural purposes at first as the main composition is not crushed concrete. They can be recommended for nonstructural applications whenever physical, mechanical and chemical properties are compatible with this application.

- Concrete mixes should be designed according to the final product to obtain. Further research should be developed over different mixes and proportions to understand much better their performance in concrete, and obtain statistical results that can bring to stronger conclusions.

\section{Conclusion}

The application of recycled aggregates in concrete mixes is widely investigated. The analysis of a case study gave the opportunity to study the possibilities of this recycled aggregate for the use in concrete mixes for concrete blocks in nonstructural applications.

A review of recent research and standards helped to identify reasons for which quality in the concrete mixes tested was so much reduced, and provided recommendations to improve the quality of this recycled aggregate and the concrete mix made with them.

This investigation contributes to recycled aggregate upcycling, in this case from mixed CDW with high content of excavated soil. Further research should be developed about the application of these recommendations to analyze the impact they can have in quality improvement of this type of recycled aggregates from mixed CDW.

\section{Acknowledgment}

J. A. Ferriz-Papi thanks Stenor Environmental Services Ltd and University of Wales Trinity Saint David for their collaboration in this project. They provided all resources for this project as partnership and supported with other help and advice. 


\section{References}

[1] N Lawson, I Douglas, S Garvin, C McGrath, D Manning, J Vetterlein "Recycling Construction and Demolition Wastes - A UK Perspective", Environmental Management and Health, 12, 2, 2001, pp 146157.

[2] European Parliament and the Council of the European Union, Directive 2008/98/EC on Waste, Official Journal of the European Union, Strasbourg, 19th November 2008, L 312/3-30.

[3] CIRIA, The Reclaimed and Recycled Construction Materials Handbook, Construction Industry Research and Information Association, London, 1999.

[4] C Hoffmann, S Schubert, A Leeman, M Motavalli "Recycled Concrete and Mixed Rubble as Aggregates: Influence of variations in Composition on the Concrete Properties and their Use as Structural Material" Construction and Building Materials, 35, October 2012, pp. 701-709.

[5] A Rao, K N Jha, S Misra, "Use of Aggregates from Recycled Construction and Demolition Waste in Concrete" Resources, Conservation and Recycling, 50, Elsevier, 2007, pp. 71-81.

[6] RILEM TC 121-DRG "Specifications for Concrete with Recycled Aggregates" Materials and Structures 27, 173, RILEM, 1994, pp. 557- 559.

[7] British Standard Institution, BS 8500-2:2015+A1:2016 Concrete - Complementary British Standard to BS EN 206. Part 2: Specification for constituent materials and concrete, BSI Standards Ltd, 2016.

[8] Spanish Parliament, Royal Decree 1237/2008, 18th July, for which the Instruction for Structural Concrete is (EHE 08) is approved, BOE 203, 22nd August 2008, pp. 35176-35178.

[9] Etxeberria, "The Role and Influence of Recycled Aggregate, in Recycled Aggregate Concrete" International RILEM Conference on the Use of Recycled Materials in Building and Structures, RILEM Publications SARL, Ed. E Vazquez, Ch F Hendriks and G M T Janssen, 2004, pp. 665-674.

[10] M. Etxeberria, E. Vazquez, A. Mari "Microstructure Analysis of Hardened Recycled Aggregate Concrete" Magazine of Concrete Research 58, 10, December, 2006, pp. 683-690.

[11] M. Etxeberria, E. Vazquez, A. Mari, M. Barra "Influence of amount of recycled coarse aggregates and production process on properties of recycled aggregate concrete" Cement and Concrete Research, 37, 2007, pp. 735-742.

[12] S. Shahidan, M. A. M. Azmi, K. Kupusamy, S S M Zuki, N Ali, "Utilizing Construction and Demolition (C\&D) Waste as Recycled Aggregates (RA) in Concrete" Procedia Engineering, 174, Elsevier, 2017, pp. 1028-1035.

[13] R. Kumar, "Influence of Recycled Coarse Aggregate Derived from Construction and Demolition Waste (CDW) on Abrasion Resistance of Pavement Concrete" Construction and Building Materials, 142, Elsevier, 2017, pp 248-255.

[14] F. M. Khalaf, A. S. DeVenny "Recycling of Demolished Masonry Rubble as Coarse Aggregate in Concrete: Review" Journal of Materials in Civil Engineering, 16, issue 4, August, 2004.

[15] A. R. Khaloo "Properties of concrete using crushed clinker brick as coarse aggregate" ACI Materials Journal, 91,2 1994, pp. 401-407.

[16] M Barra de Oliveira, E Vázquez "The influence of Retained Moisture in Aggregates from Recycling on the Properties of New Hardened Concrete" Waste Management, 16, 1-3, 1996, pp. 113-117. 
[17] M. Zakaira, J. G. Cabrera "Performance and Durability of Concrete Made with Demolition Waste and Artificial Fly Ash-Clay Aggregates" Waste Management, 16, 1-3, 1996, pp. 151-158.

[18] A. Mueller, A. Schnell, K Ruebner "The Manufacture of lightweight aggregates from Recycled Masonry Rubble" Construction and Building Materials, 98, November 2015, pp. 376-387.

[19] R. V. Silva, J de Brito, R K Dhir "Properties and Composition or Recycled Aggregates from Construction and Demolition Waste" Construction and Building Materials, 65, 2014, pp 201-217.

[20] W Jin, C Meyer, S Baxter "Glasscrete"-Concrete with Glass Aggregate" ACl Materials Journal, March/April 2000, pp 208-213.

[21] T. C. Hansen, Recycling of Demolished Concrete and Masonry, RILEM Report of Technical Committee 37-DRC, Taylor and Francis, 1992.

[22] Environment Agency \& WRAP, Quality Protocol. Aggregates from inert waste, Defra, Welsh Government and NIEA, UK, October 2013.

[23] Concrete Block Association, Aggregate Concrete Blocks. Aggregate Block Sustinability, CBA, UK, February 2013.

[24] V. W. Y. Tam, K. Wang, C. M. Tam "Assessing relationships among properties of demolished concrete, recycled aggregate and recycled aggregate concrete using regression analysis", Journal of Hazardous Materials, 152, 2, April 2008, pp. 703-714.

[25] B. Monalisa, S. K. Bhattacharyya, A. K. Minocha, R. Deoliya, S. Maiti "Recycled Aggregate from C\&D waste \& its Use in Concrete - A Breakthrough towards Sustainability in Construction Sector: A review" Construction and Building Materials, 68, October 2014, pp 501-516.

[26] A. Todhunter, M. Crowley, M. Gholamisheverini, and F. Sartipi, "Advanced technological implementation of construction and demolition waste recycling," Journal of Construction Materials, vol. 1, no. 1, 2019, doi: https://doi.org/10.36756/JCM.v1.1.3.

[27] F. Sartipi, "Automatic sorting of recycled aggregate using image processing and object detection," Journal of Construction Materials, vol. 1, pp. 3-3, 2020, doi: https://doi.org/10.36756/JCM.v1.2.1.

[28] T. Boulos, F. Sartipi, and K. Khoshaba, "Bibliometric analysis on the status quo of robotics in construction," Journal of Construction Materials, vol. 1, pp. 2-3, 2020.

[29] F. Sartipi, "A brief critical view on the carbon-conditioning of recycled aggregate using pressure chamber," Journal of Construction Materials, vol. 2, pp. 1-4, 2020, doi: https://doi.org/10.36756/JCM.v2.1.4.

[30] F. Sartipi and A. Sartipi, "Brief review on advancements in construction additive manufacturing," Journal of Construction Materials, vol. 1, pp. 2-4, 2020, doi: https://doi.org/10.36756/JCM.v1.2.4

[31] A. Gharizadeh, F. Sartipi, E. Ayoubi, and A. Severino, "The chemical reactor design configuration of $\mathrm{CO} 2$ concrete green solution," Journal of Construction Materials, vol. 1, pp. 2-5, 2020, doi: https://doi.org/10.36756/JCM.v1.2.5. 
[32] A. Todhunter, M. Crowley, and F. Sartipi, "Construction productivity indices in socialism compared with capitalism," Journal of Construction Materials, 2019, doi: https://doi.org/10.36756/JCM.v1.1.2.

[33] F. Sartipi, "Diffusion of Innovation Theory in the Realm of Environmental Construction," Journal of Construction Materials, vol. 1, pp. 4-2, 2020, doi: https://doi.org/10.36756/JCM.v1.3.2 .

[34] F. Sartipi, A. Ghari Zadeh, and M. Gamil, "Electrical resistance of graphene reinforced cement paste," Journal of Construction Materials, 2019.

[35] F. Sartipi, "Feasibility study of concrete recycling in post-disaster reconstruction

" Journal of Housing and Rural Environment, vol. 34, 2016.

[36] V. Tam, F. Sartipi, and K. N. Le, "Gaps between supply and demand of recycled aggregate: Sydney metropolitan case study," Presented at the CRIOCM 2018, 2018.

[37] F. Sartipi, "Influence of 5G and IoT in construction and demolition waste recycling-conceptual smart city design," Journal of Construction Materials, vol. 1, pp. 4-1, 2020, doi: https://doi.org/10.36756/JCM.v1.4.1.

[38] F. Sartipi, "Organizational structure of construction entities based on the cooperative game theory," Journal of Construction Materials, vol. 1, no. 2, 2020, doi: https://doi.org/10.36756/JCM.v1.3.3

[39] J. Luliano, A. Singh, and F. Sartipi, "Political-economical evaluation of CO2 capture in Australian building sector," Journal of Construction Materials, vol. 1, pp. 3-2, 2020, doi: https://doi.org/10.36756/JCM.v1.3.2.

[40] F. Sartipi and E. Zarqam, "Recycled concrete and the advantages of using recycled aggregates," presented at the 3rd International congress on architecture, civil engineering and urban development, Tehran, 2016.

[41] M. Gamil, A. Ghari Zadeh, and F. Sartipi, "A review on graphene reinforced cement composite: technical approach for ecofriendly construction," Journal of Construction Materials, 2019.

[42] $\quad$ F. Sartipi and M. Soomro, "Solutions for barriers against the wider use of recycled aggregate."

[43] M. Sartipi and F. Sartipi, "Stormwater retention using pervious concrete pavement: Great Western Sydney case study," Case Studies in Construction Materials, vol. 11, p. e00274, 2019.

[44] A. Todhunter, M. Crowley, F. Sartipi, and K. Jegendran, "Use of the by-products of postcombustion carbon capture in concrete production: Australian case study," Journal of Construction Materials, vol. 1, no. 1, 2019, doi: https://doi.org/10.36756/JCM.v1.1.1.

[45] F. Sartipi, K. Palaskar, A. Ergin, and U. Rajakaruna, "Viable construction technology for habitation on Mars: Fused Deposition Modelling," Journal of Construction Materials, vol. 1, no. 2, 2020. 